\section{Military Technical College Kobry El-Kobbah, Cairo, Egypt}

\section{$8^{\text {th }}$ International Conference on Civil and Architecture \\ Engineering \\ ICCAE-8-2010}

\title{
3-D Nonlinear Numerical Analysis to study the Performance of Twin Tunnel System
}

By

\author{
$\begin{array}{lll}\text { S. M. Atrash* S. A. Mazek** } & \text { M. K. El Ghamrawy*** } \quad \text { H. M. Farag**** }\end{array}$
}

\section{Abstract:}

Tunneling in loose soil is a sophisticate process leading to unexpected collapse for surface and subsurface structures. However, it is necessary to investigate the geotechnical problems related to tunneling. Tunneling process needs to more engineering insight analysis. Several numerical analyses have been conducted to model the soil-structure interaction behavior. However, this study presents a case history along El-Azhar road tunnels.

In the present study, the finite element model (FEM) is proposed to predict the performance of the tunnel system under the twin tunnel construction. The case history presented and discussed in this study gives a rare opportunity to understand the performance of the tunnel system. The constitutive model for this analysis utilizes elasto-plastic materials.

A yielding function of the Mohr-Coulomb type and a plastic potential function of the Drucker-Prager type are employed. A linear constitutive model is employed to represent the tunnel liner.

The response of El-Azhar road tunnels system is described and presented to investigate the ground movement caused by tunneling. The ground movement is calculated using 3-D finite element analysis (FEA). The results obtained by the 3-D nonlinear numerical model are compared with those obtained by the field measurement to assess the accuracy of the proposed 3-D FEM. A good agreement between the results obtained by the 3-D FEA and those by the field measurements was obtained.

\section{Keywords:}

Twin tunnels system, numerical modelling, finite element analysis, deformations. 
* Ph.D. Student, Civil Engineering Department, Military Technical College, Cairo, Egypt

** Assistance Professor, Civil Engineering Department, Military Technical College, Cairo, Egypt

*** Professor, Civil Engineering Department, El-Azhar University, Cairo, Egypt

**** Ph.D. Lecturer, Civil Engineering Department, Military Technical College, Cairo, Egypt

\section{INTRODUCTION}

El-Azhar road tunnels have been constructed by tunnel boring machine (TBM) in a densely populated historical area in Cairo city. The twin road tunnels extend from Salah Salem Street to Opera square at downtown. Each tunnel is $2.7 \mathrm{~km}$ long. Only one-km span of the road tunnels were constructed using cutand-cover technique.

Tunneling leads to ground movement due to the associated stress change. The numerical techniques have been widely used to predict the ground movements [1, 2, 3, 4, 5, 6, 7 and 8]. Finite element method is considered the most appropriate analytical technique to solve geotechnical problems [9, 10, 11, 12, 13 and 14]. Modeling of geotechnical properties and tunneling procedure is the sophisticated problem [15, 16, and 17]. In this study, El- Azhar road tunnels in central Cairo city are considered. The tunnel system performance is studied. The tunnel system is modelled using 3-D nonlinear finite element analysis (FEA) under the shadow of the case history, to understand the performance of the tunnel systems. In the 3-D nonlinear FEA, the tunneling process and the interaction effects between the tunnel and the soil around the tunnel are investigated. The 3-D nonlinear FEA is used to estimate the vertical displacement at ground surface due to tunneling. A comparison between the results calculated by the 3-D nonlinear FEA and the results recorded by field measurements to assess the accuracy of the proposed 3-D nonlinear FEA. The typical geotechnical and the soil properties used in this study are presented. However, the results calculated by the finite element analysis agree well with those obtained by the field measurements.

\section{FINITE ELEMENT MODEL}

The finite element computer program (COSMOS /M) [18] is used in this study. The finite element model takes into account the effects of the vertical overburden pressure, the lateral earth pressure, the nonlinear properties of the 
soils, and the linear properties of the tunnel liner. The soil, the tunnel lining, and the interface medium are simulated using appropriate finite elements model. Numerical modeling of the tunnels reflects the ground continuum and the tunnel liner. In addition, the compatibility and the equilibrium condition at the interface between the soil and the tunnel system are idealized in the numerical model. A nonlinear stress-strain constitutive model is adopted for the soil around the tunnel systems. A yield function of the Mohr-Coulomb type and a plastic potential function of the Drucker-Prager type are employed. In addition, linear elastic behavior is assumed for the tunnel liners.

Solid elements are used for modeling the soil media and the thick shell elements for modeling the tunnel liner. The thick shell element models both membrane (in plane) and bending (out plane) behavior of the tunnel structure. The solid element is chosen since it posses in-plane and out-of-plane stiffness, and allows for both in-plane and out-of-plane loads. The solid element is prismatic in shape. The prismatic solid element and the triangular shell element interface are used between the soil media and the tunnel liner to ensure the compatibility conditions at the interface between them as well as the associated stress and strains along the interface surface.

The vertical boundaries of the 3-D finite elements model are restrained by roller supports to prevent the lateral movement. The horizontal plane at the bottom of the mesh represented a rigid bedrock layer and the movement at this plane is restrained in all directions. The movement at the upper horizontal plane is free to simulate a free ground surface, as shown in Fig. 1. In the finite element analysis, the loading attributed to the construction process is considered.

\section{PROPERTIES OF TUNNEL LINING AND SOIL}

The case study discussed in this paper was constructed at central Cairo city. The project area under analysis lies within the alluvial plain, which covers the major area of the low land portion of the Nile valley in Cairo vicinity [19, 20, and 21]. As shown in Fig. 2. Site investigations along the project alignment have indicated that the soil profile consists of a relatively thin surficial fill layer ranging from two to four meters in thickness. A natural deposit of stiff, overconsolidated silty clay underlies the fill. This deposit includes occasional sand and silt partings of thickness from four to ten meters. Beneath the clay layer, there is thick alluvial sand that extends down to bedrock, which is well below the road tunnels. The upper few meters of this alluvial sand are parts of a transition layer of highly interbedded clay silt and fine sand. Below the transition layer, the alluvial sand layer is more uniform with coarse to fine sand, which occasionally 
contains layers of silt to clayey silt that varies in thickness from a few centimeters to several decimeters. The ground water table varies from one meter to four meters from the ground surface.

The main soil parameters required to model the performance of the case study are presented in Table 1 .

The constitutive relationship adopted in the analysis is an elasto-plastic model. The friction angles $(\phi)$ adopted for the layers have been obtained using laboratory test results from reconstituted samples. The vertical initial drained modulus $\left(\mathrm{E}_{v}\right)$ is related to the effective stress based on Janbu's empirical equation [22], which is given by

$E_{v}=m p_{a}\left(\frac{\sigma_{3}}{p_{a}}\right)^{n}$

In which, the modulus number (m) and the exponent number (n) are both pure numbers and $\left(\mathrm{P}_{a}\right)$ is the value of the atmospheric pressure expressed in appropriate units.

The diameter of tunnel liner (D), the characteristic of the tunnel liner and the excavation diameter of the tunnel $\left(\mathrm{D}_{0}\right)$ are presented in Table 2 .

The tunnel liners are assumed to behave in a linear manner in the 3-D nonlinear finite element analysis.

The ground surface displacement due to the construction of the tunnel is calculated in this study.

\section{GEOMETRIC BOUNDARIES OF 3-D MODEL}

\subsection{Dimension of model}

The 3-D finite element mesh used in the analysis models a soil block with width, height and depth in $\mathrm{x}, \mathrm{y}$, and $\mathrm{z}$ directions, respectively, as shown in Fig. 1. Studies have been adopted for the road tunnels located at 20 meter depth from the ground surface. Drain analysis is adopted in the numerical model, where the tunnels pass through the sandy soil layer. The ground loss is considered in this study. The ground loss will be discussed in detail in section (4.3). The suitable geometric boundaries (model width and model height) are studied to reflect the accurate performance of the tunnel system. The study is also conducted to determine the optimum model width beyond which no changes in stresses are occurred. The 3-D finite element analysis is used to choose the suitable width so as to realistically reflect the behavior of the tunnel system. The soil depth beneath the invert of the twin tunnels is 2.5 times diameter of the tunnel $[5,13]$.

The model width is varied from 40 meters to 120 meters. The calculated surface settlements along the centreline of the twin tunnel for different model 
widths are shown in Fig. 3. As the model width exceeds 120 meters there is no change in the estimated surface settlement. The calculated crown settlements of the twin tunnels for different model widths are presented in Fig. 4. The results also show that as the model width exceeds 120-meters there is hardly any change in the estimated crown settlement of the tunnel. The calculated invert heaves of the twin tunnel for different model widths are also presented in Fig 5. The results also show when the model width exceeds 120-meters there is no change in the estimated invert heave. Hence, the 120 meter model width is chosen to realistically reflect the performance of the tunnel system. The 120 meter model width and the fifty-meter model height are used in the analysis to compare the results obtained by 3-D finite element analysis and the field measurement.

\subsection{Mesh size}

The suitable mesh size is discussed to reflect the accurate performance of the road tunnel system using the 3-D finite element analysis. The element size is varied $(2 \mathrm{~m}, 3 \mathrm{~m}, 4 \mathrm{~m}$, and $5 \mathrm{~m}$ ) along the outer boundary of the soil block, as shown in Fig. 1. The element size is also varied $(1 \mathrm{~m}, 1.5 \mathrm{~m}, 2 \mathrm{~m}, 2.5 \mathrm{~m}$, and 3 $\mathrm{m})$ along tunnel liner, as shown in Fig.1. Based on different element size, the calculated surface settlement is presented in Table 3. The three- meter element size along the outer soil block boundary is chosen to reflect the accurate tunnel system performance. The one-meter element size along the tunnel liner is also selected to simulate the actual performance of the road tunnel system.

\subsection{Ground loss impact}

The construction of tunnel leads to a subsurface movement due to groundloss. The groundloss (VL) is the ratio of the difference between volume of excavated soil and tunnel volume over the excavate soil volume. The ground loss ranged from $1.5 \%$ to $4.5 \%$ and reached to $6 \%$ at some location along the tunnel projects in Cairo city [15]. The ground loss impact on the behavior of the tunnel system is investigated to assess the accuracy of the 3-D nonlinear finite element model to understand the performance of the tunnel system.

Surface settlement, crown settlement, and invert heave of the twin tunnel are calculated by the 3-D finite element analysis. The suitable ground loss is studied to reflect the accurate performance of the tunnel system. In the parametric study, the ground loss is varied from $1 \%$ to $6 \%$ to choose the suitable ground loss. The ground loss of $3 \%$ is chosen to realistically reflect the performance of the road tunnel system. The calculated surface settlements for different ground loss for the road tunnels are analyzed and presented in Fig. 6. The calculated surface settlement due to tunneling is 
affected by the ground loss impact. The results show that the increase of the ground loss due to tunneling leads to increase the maximum surface settlements.

\section{STRESSES IN SOIL}

The stress changes in soil around the tunnel system due to tunneling are investigated to study the detailed soil behavior. The stresses in the soil have undergone two stages of change.

The first stage corresponds to the construction of the first tunnel (northern tunnel) and the second stage to the construction of the second tunnel (southern tunnel). At the first stage, the loading steps of the tunnel construction are simulated as fallows: Firstly, the initial principal stresses are computed with the absence of the twin tunnels. Secondly, the excavation of the northern tunnel is simulated by the removal of those elements inside the boundary of the northern tunnel surface. Thirdly, the movement and stress changes induced in soil media are calculated. Fourthly, the calculated changes in stresses are then added to the initial principal stresses computed from the first step to determine the final principal stresses resulting from the northen tunnel construction.

The final induced principal stresses at the place of the southern tunnel are considered as the initial principal stresses for the second stage. The loading steps of the southern tunnel construction are then simulated as mentioned above in first stage and the final stresses due to the construction of the southen tunnel are computed.

The initial in-situ stresses of the excavated tunnel boundary before tunneling are calculated and plotted in Fig. 7 a. The vertical stress change after tunneling is calculated and presented in Fig $7 \mathrm{~b}$. The final vertical stress change after tunneling is calculated and compared with the initial insitu vertical stress before tunneling, as shown in Fig 7. The results show that the soil above the crown of the road tunnels settles downward and the soil under the invert of the road tunnels excavation heaves.

\section{3-D FINITE ELEMENTS MODEL VERVICATION (CASE HISTORY)}

In this study, El-Azhar road tunnels are studied through a comparison between the results calculated by the 3-D nonlinear FEA and the results recorded by field measurements.

The computed surface settlements are compared with those obtained by the field measurements so as to understand the behavior of the road tunnels, as shown in Fig. 8. 
This comparison is used to assess the accuracy of the proposed numerical model. The comparison shows that there is a good agreement between the computed and measured readings.

Generally, the calculated surface settlement due to the tunnel construction underestimates by up to $10 \%$ with respect to the field measurement for this case study. This discrepancy between calculated and measured readings may be caused by the accuracy of soil strength parameters, soil stress parameters, soil modelling, or instrumentation.

The final vertical displacement along the centreline of the twin tunnels at different levels is also presented in Fig. 9. The results show that the soil above the crown of the road tunnels excavation moves down and the soil under the invert of the road tunnels excavation heaves due to stress change as discussed in section 5 .

\section{CONCLUSION}

A 3-D nonlinear finite element analysis is used to study the performance of the tunnel system under shadow of the case studied. The analysis considered the changes in stress, the non-linear behavior of the soil, and the construction progress. The following conclusions can be drawn regarding the performance of the tunnel under the effects of different factors.

1- The 3-D nonlinear numerical model is applicable to analyze and predict the detailed performance of the tunnel system for the case studied.

2- The results calculated by the proposed 3-D nonlinear FEA have a good agreement with the field data. The predicted surface settlements underestimate by up to $10 \%$ for the case history with respect to the field measurement.

3- Ground loss is an important parameter effect on the performance of the tunnel system. An increase of ground loss from 1\% to $6 \%$ increases the estimated surface settlements due to tunnelling by up to $50 \%$. A smaller ground loss due to tunneling a smaller calculated surface settlement.

4- The minimum width of the 3-D nonlinear model is set to be ten times the tunnel diameter in the 3-D numerical model. 


\section{REFERENCES}

[1] El-Nahhas, F. M. 1986. Spatial mode of ground subsidence above advancing shielded tunnels. Proc. of International. Congress on Large underground Opening, Fireze, Italy, Vol. 1, pp. 720-725.

[2] Berant, S., and Cambou, B. 1998. Soil-Structure Interaction in Shield tunneling in soft ground. Computers and Geotechnics. Vol. 22. No. 34. pp. 221-242.

[3] Abu - Farsakh, M.Y., Tumay, M.T. and Fellow. 1999. Finite element analysis of ground response due to tunnel excavation in soils. Proc of the International Journal for Numerical and Analytical Methods in Geomechanics. Vol. 23, pp. $524-525$.

[4] Galli.G, Grimaldi. A, and Leonardi. A. 2004. Three Dimensional Modeling of Tunnel Excavation and Lining. Computer and Geotechnics. 31, pp. $171-183$.

[5] Mazek, S.A, Law. K. T, and Lau. D. T. 2004. Numerical Analysis of Crossing Tunnel Performance. Proc of the $5^{\text {th }}$ ICCAE conf. 23- 25 Nov. pp. $378-390$.

[6] Mazek, S.A, and El-Ghamrawy, M. K. and Law K. T. 2009. 3-D elasto-plastic model of tunnel performance under shadow of case history, Proc of the 17th International Conference on Soil Mechanics and Geotechnical Engineering, pp. $1829-1833$.

[7] Abdel-Meguid, M, Rowe, R. K. and Lo, K. Y. 2002. 3-D Effects of Surface Construction Over Existing Subway Tunnels, Proc of the International Journal of Geomechanics Volume 2, Number 4, pp. 447-469

[8] Mroueh, H and Shahrour, I. 2008. A simplified 3-D model for tunnel construction using tunnel boring machines. Tunneling and Underground Space Technology 23, pp. $38-45$.

[9] Oettl and Hofstetter.1998. A comparison of elastic-plastic soil models for 2-D FE analyses of tunneling. Computers and Geotechnics 23, pp. $19-38$.

[10] Addenbrooke, T. I., and Potts, D. M. 2001. Twin tunnel interaction surface and subsurface effects. The International Journal of Geomechanics. Vol. 1, No2, pp. 249 - 271. 
[11] Mazek, S.A. 2004. 3-D Elasto-Plastic Finite element Analysis of Crossing Tunnels. Proc of the $5^{\text {th }}$ ICCAE conf. 23- 25 Nov. pp. 364 377.

[12] Karakus, M., and Fowell, R.J. 2005. Back analysis for tunneling induced ground movement and stress redistribution. Tunneling and Underground Space Technology 20, pp. 514 - 524.

[13] Mazek, S.A., Belal, A.M., Kamal, I.M., and Amer, N.H. 2006. Numerical Modeling of Soil-Tunnel Interaction under new surface load. Procp of the 6th ICCAE conf16-18, May, pp. 248 - 257.

[14] Migliazza, M., Chiorboli, M., and Giani, G. P. 2009. Comparison of analytical method, 3D finite element model with experimental subsidence measurements resulting from the extension of the Milan underground. Computers and Geotechnics 26, pp. $113-124$.

[15] El-Nahhas, F.M. 1999. Soft Ground Tunneling in Egypt Geotechnical Challenges and Expectations. Proceeding of tunneling and underground space technology, Vol. 14, No. 3, pp. 245-256.

[16] Contini. A, Cividini. A, and Gioda. G. 2007. Numerical Evaluation of the Displacement due to Soil Grouting and to Tunnel Excavation. Journal of Geomechanics. Vol. 7, No. 3, 2007, pp. 217-226.

[17] Mazek, S.A, and Tehawy, E.M. 2008. Impact of Tunneling Running Side-by-Side to An Existing Tunnel on Tunnel Performance using Non-linear Analysis. Proc of the $7^{\text {th }}$ ICCAE. 27-29 May, 2008. Cairo, Egypt.

[18] COSMOS/M program.. Structural Research and Analysis Corporation. Los Angles, California. USA.

[19] El-Nahhass, F.M. 1994. Some geotechnical aspects of shield tunneling in the Cairo area. Proceedings of the international congress on tunneling and ground condition, Abdel Salam (ed.), Cairo, Egypt. Published by Balkema, Rotterdam.

[20] Mazek, S.A., Law, K.T., and Lau, D.T. 2001. 3-D Analysis on the Performance of a Grouted Tunnel. Proceeding of Canadian Geotechnical Conference. An Earth odyssey 2001. Calgary, Alberta, Canada, pp. 111-118.

[21] National Authority for Tunnels (NAT), 1993, 1999, and 2003 Project Documents. 
[22] Janbu, N. 1963. Soil compressibility as determined by oedometer and triaxial tests. European conference on soil mechanics and foundation engineering. Wiesbaden. Germany. vol. 1, pp. $19-25$.

Table (1): Geotechnical properties

\begin{tabular}{|c|c|c|c|c|}
\hline \multirow{2}{*}{ Soil parameters } & \multicolumn{3}{|c|}{ Type of soil } \\
\cline { 2 - 5 } & Fill & Clay & Silty sand & Sand \\
\hline Modulus number (m) & 300 & 325 & 350 & 500 \\
\hline Exponent number (n) & 0.74 & 0.60 & 0.60 & 0.53 \\
\hline Effective cohesion (c) $\left(\mathbf{t} / \mathbf{m}^{2}\right)$ & 1 & 0 & 0 & 0 \\
\hline Effective angle of internal friction $(\phi)$ & 25 & 26 & 32 & 37 \\
\hline Poisson's ratio $(\nu)$ & 0.40 & 0.35 & 0.30 & 0.30 \\
\hline Soil bulk density $/ \mathbf{b}\left(\mathbf{t} / \mathbf{m}^{3}\right)$ & 1.80 & 1.90 & 1.85 & 2.0 \\
\hline
\end{tabular}

Table (2): Characteristics of the road tunnels

\begin{tabular}{|c|c|c|c|c|c|c|}
\hline Tunnel & $E_{b}\left(\mathrm{t} / \mathrm{m}^{2}\right)$ & $v$ & $f_{c}\left(\mathrm{t} / \mathrm{m}^{2}\right)$ & $(\mathrm{t}) \mathrm{cm}$ & $\begin{array}{c}\text { Diameter of tunnel } \\
\text { liner (D) m }\end{array}$ & $\begin{array}{c}\text { Excavation } \\
\text { diameter }\left(\mathrm{D}_{0}\right) \mathrm{m}\end{array}$ \\
\hline Road & $2.1 \times 10^{6}$ & 0.18 & 4000 & 25 & 9.06 & 9.56 \\
\hline
\end{tabular}


Table (3): Estimated settlement of ground surface considering different elements sizes (El-Azhar road tunnels)

\begin{tabular}{|c|c|c|c|c|c|c|c|c|c|c|c|c|c|}
\hline \multirow{2}{*}{$\begin{array}{c}\text { Mesh } \\
\text { Size } \\
(\mathrm{m})\end{array}$} & $\begin{array}{l}\text { Element size } \\
\text { along outer } \\
\text { boundary of }\end{array}$ & \multicolumn{5}{|c|}{$5 \mathrm{~m}$} & \multicolumn{4}{|c|}{$4 \mathrm{~m}$} & \multicolumn{3}{|c|}{$3 m^{* * *}$} \\
\hline & $\begin{array}{l}\text { Element size } \\
\text { along tunnel } \\
\text { Liner model }\end{array}$ & $1 \mathrm{~m}$ & $1.5 \mathrm{~m}$ & $2 \mathrm{~m}$ & $2.5 \mathrm{~m}$ & $3 \mathrm{~m}$ & $1 \mathrm{~m}$ & $1.5 \mathrm{~m}$ & $2 \mathrm{~m}$ & $2.5 \mathrm{~m}$ & $1 \mathrm{~m}^{* * *}$ & $1.5 \mathrm{~m}$ & $2 \mathrm{~m}$ \\
\hline \multicolumn{2}{|c|}{$\begin{array}{l}\text { Surface Settlement } \\
(\mathrm{mm})\end{array}$} & 8.7 & 8.4 & 8.1 & 7.5 & 7.1 & 9.3 & 8.9 & 8.5 & 8.0 & $9.7^{\text {*k*k }}$ & 9.3 & 8.9 \\
\hline
\end{tabular}

*** Selected elements size of 3-D finite element mode1

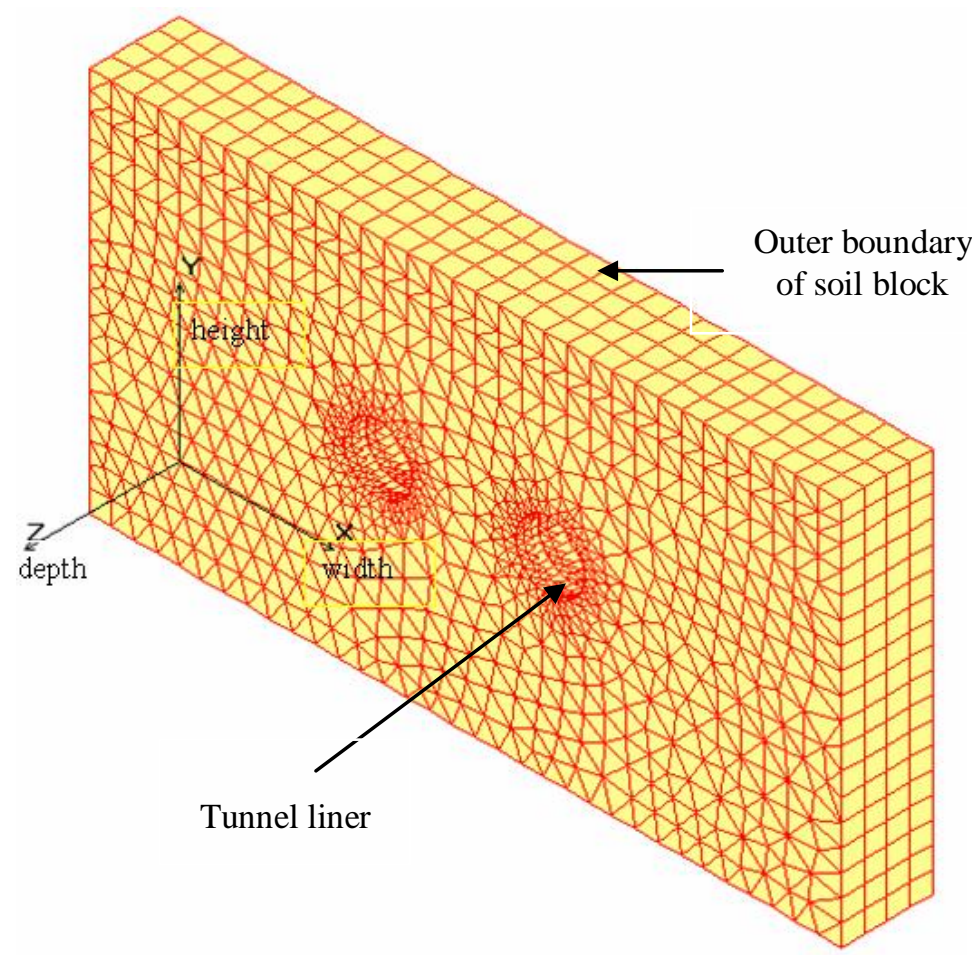

Figure (1): 3-D finite element model of El-Azhar road tunnels 


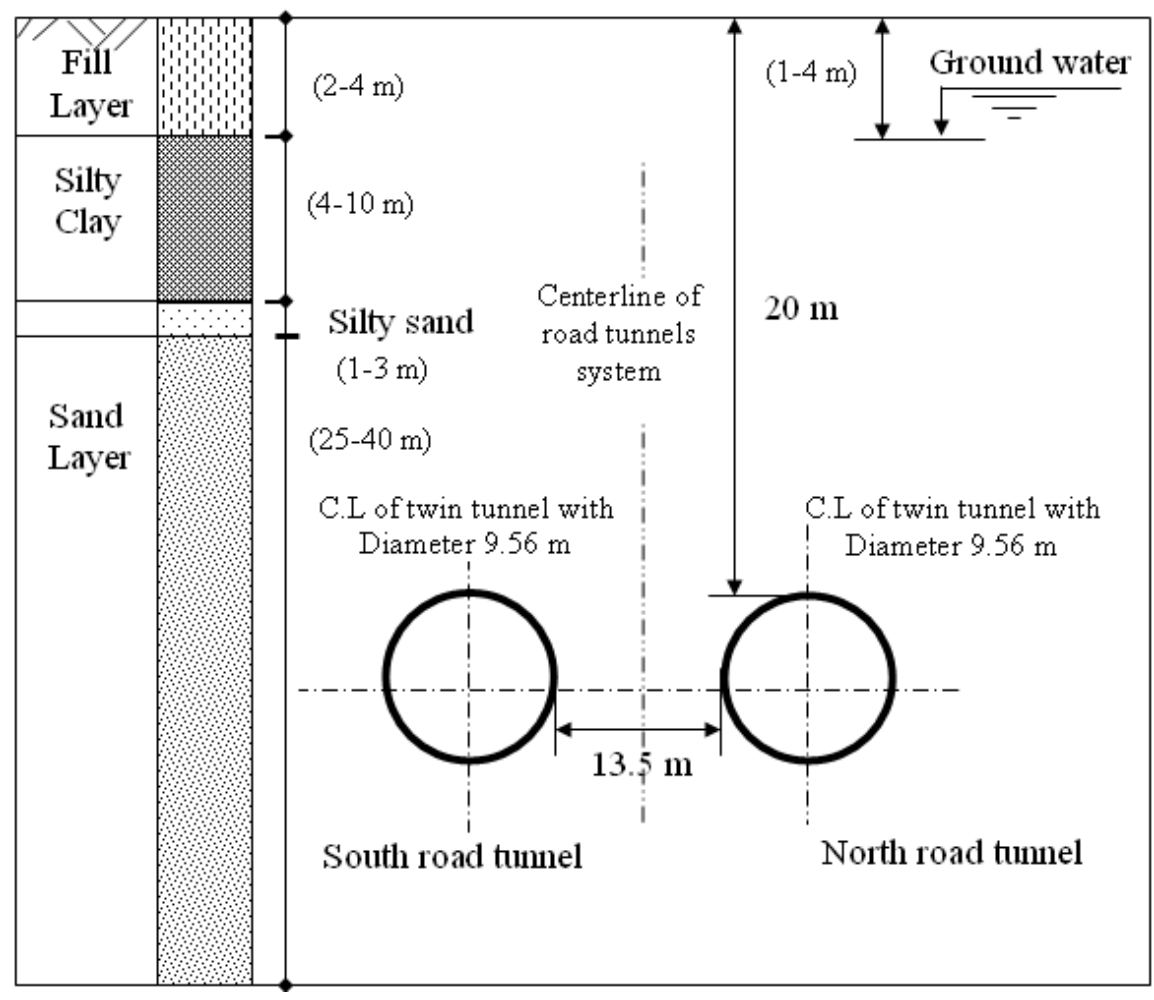

Figure (2): Soil profile at central Cairo City

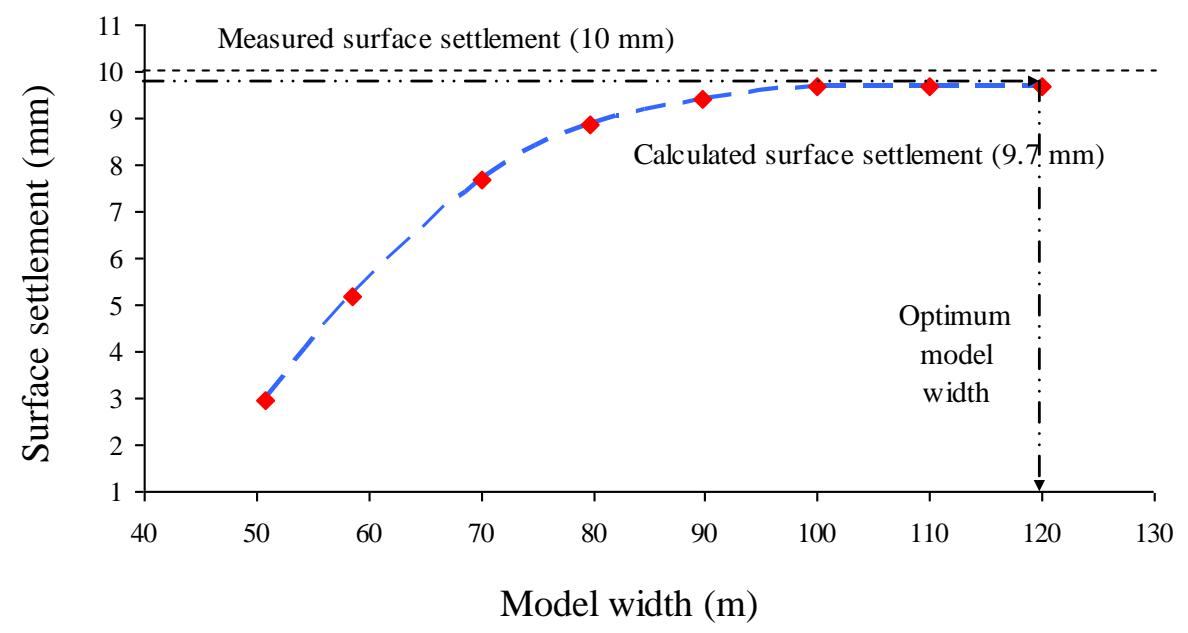

Figure (3): Calculated surface settlement due to road tunnels construction with different model widths 


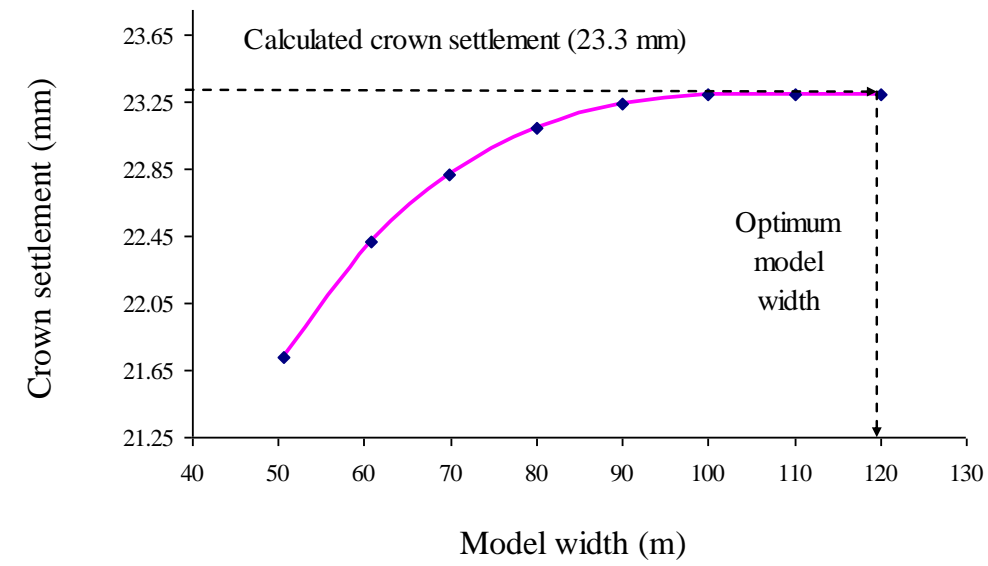

Figure (4): Calculated crown displacement of the road tunnels construction with different model widths

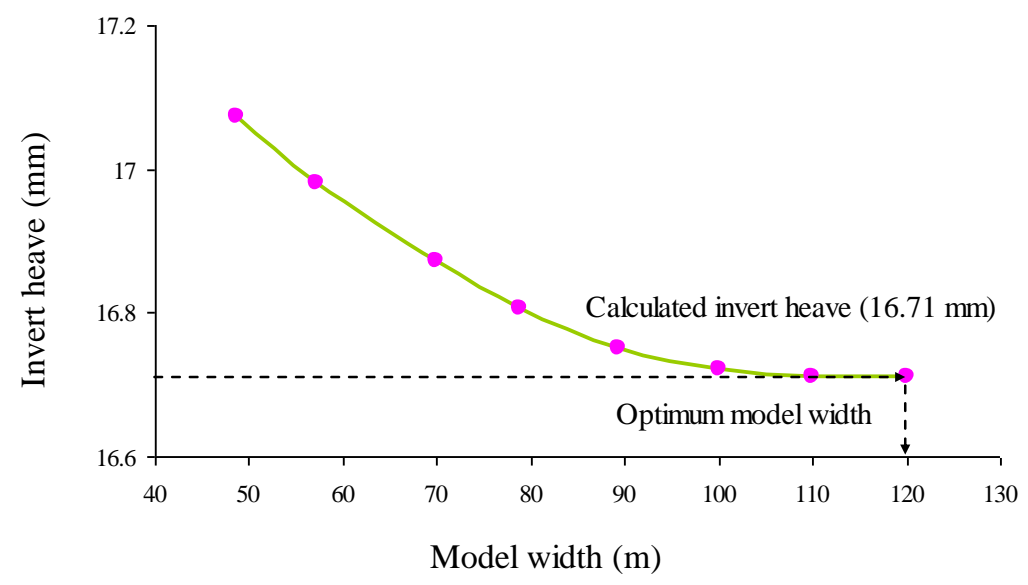

Figure (5): Calculated invert displacement due to road tunnels construction with different model widths

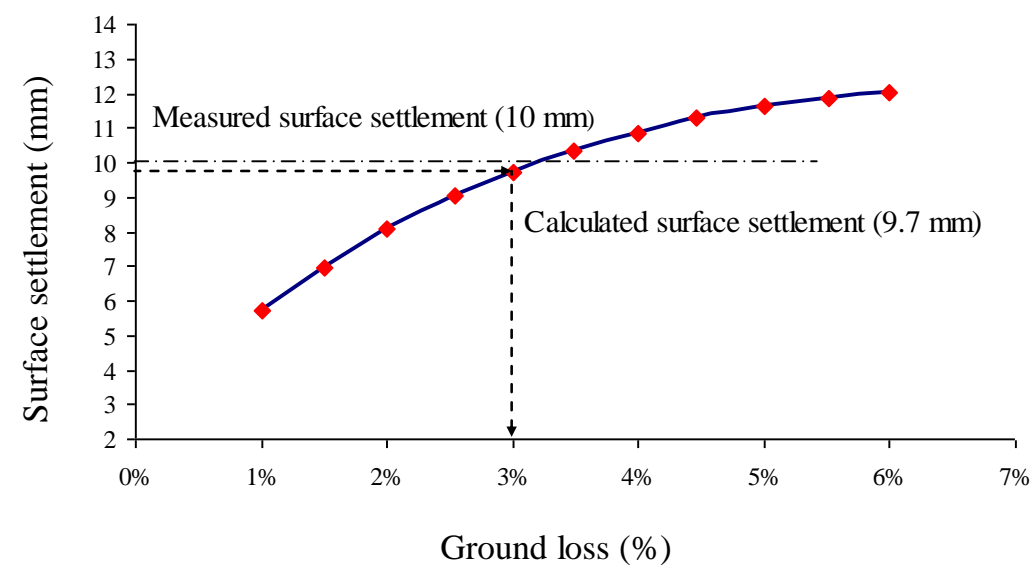

Figure (6): Calculated surface settlement due to different ground losses (road tunnels) 


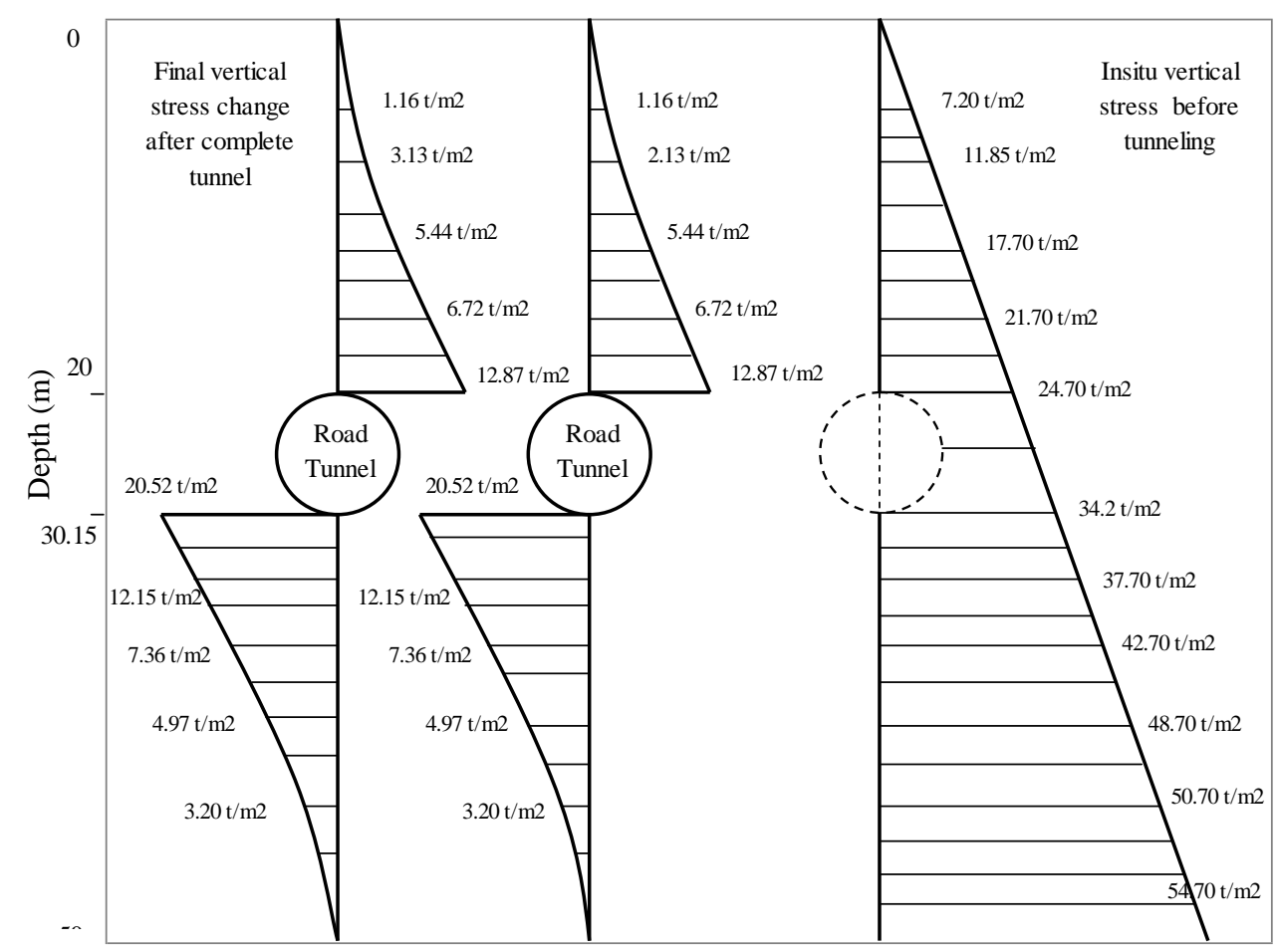

b) Final vertical stress change after complete tunnelling

a) insitu vertical stress before

Figure (7): Vertical stress before and after tunnelling (El-Azhar road tunnels)

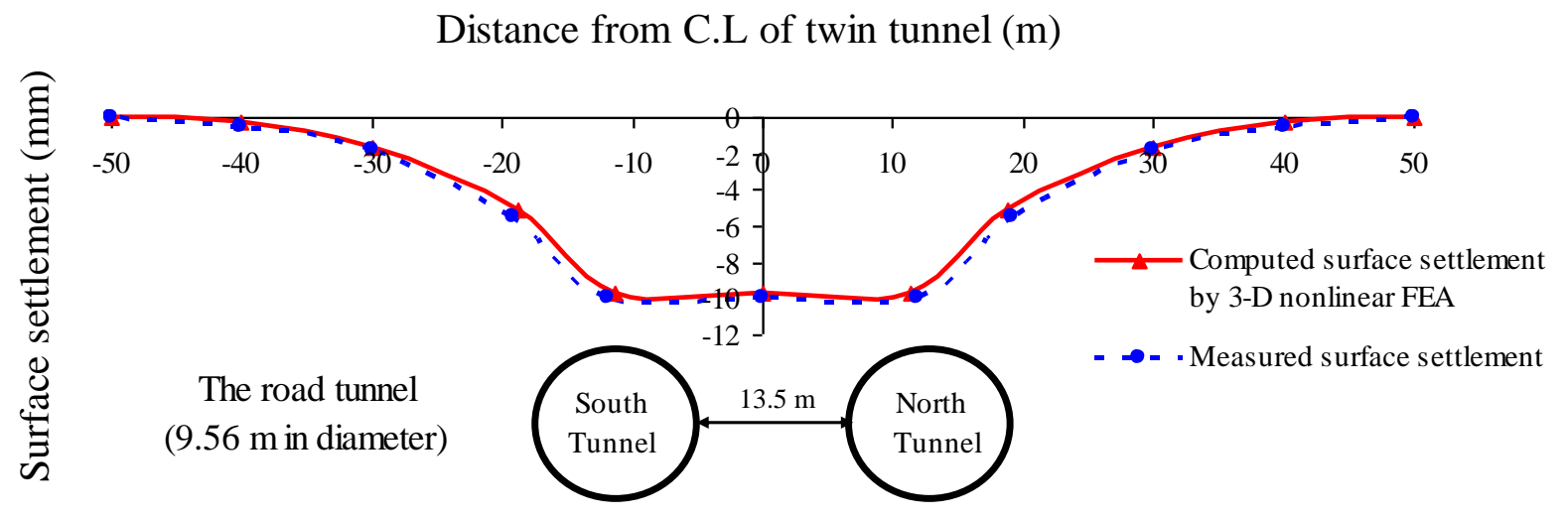

Figure (8): Comparison between measured and calculated surface settlement due to the construction of El-Azhar road tunnels 
Distance from C.L of tunnel (m)

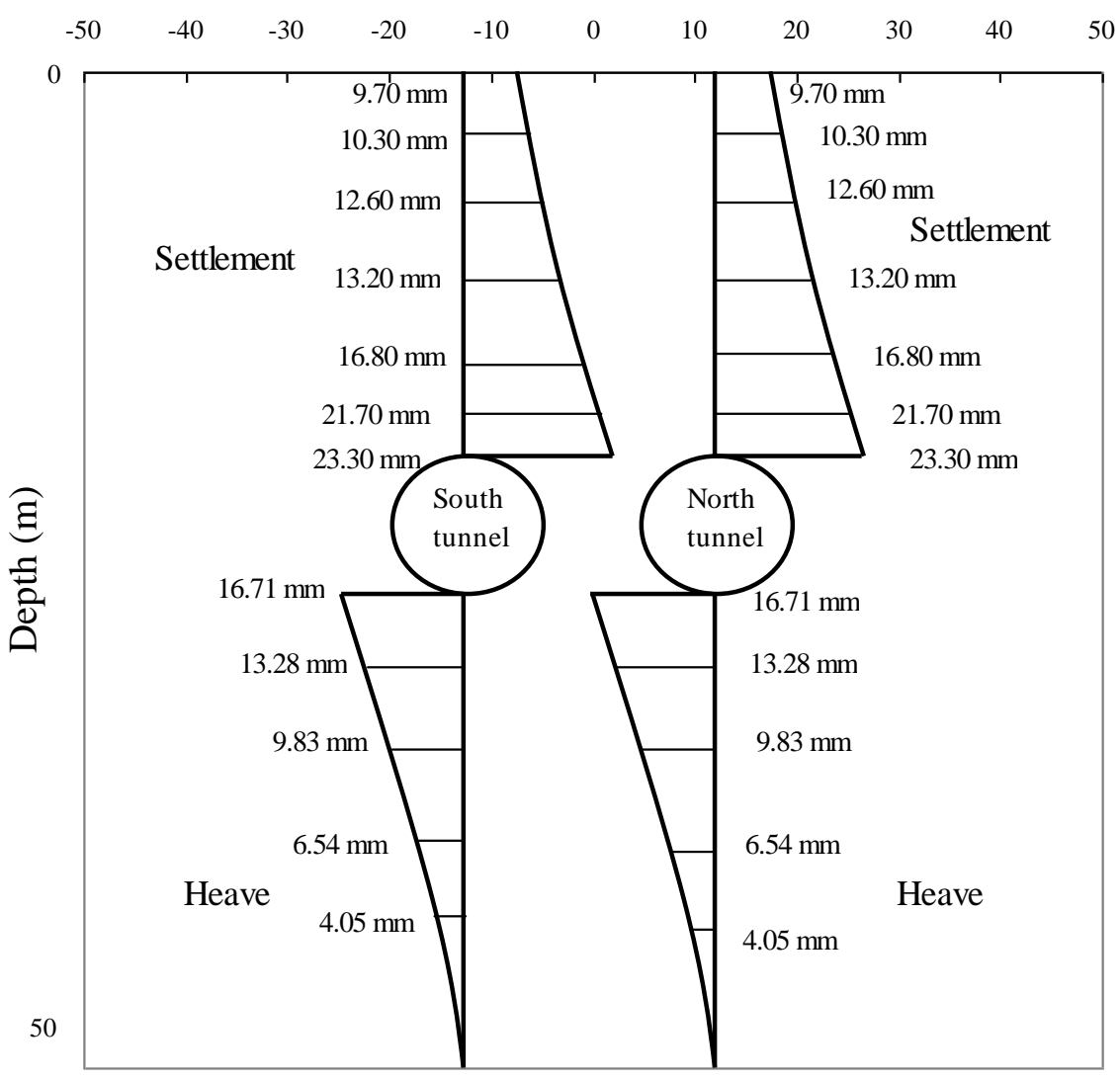

Figure (9): Calculated vertical displacement at different levels along

The centreline of the twin road tunnels 